\title{
Water Policy Under Risk and Uncertainty A Dynamic Evaluation Model of Fodder Cultivation in Oman
}

\author{
Kheiry Hassan M. Ishag ${ }^{1,2} \&$ Hag Hamad Abdelaziz ${ }^{1}$ \\ ${ }^{1}$ Department of Agricultural Economics, Faculty of Agricultural Studies, Sudan University of Science and \\ Technology, Sudan \\ ${ }^{2}$ Dhofar Cattle Feed Company, Oman \\ Correspondence: Kheiry Hassan M. Ishag, Dhofar Cattle Feed Company, Oman. PhD candidate, Department of \\ Agricultural Economics, Faculty of Agricultural Studies, Sudan University of Science and Technology, Sudan. \\ E-mail: Kheiryishag@hotmail.com
}

Received: June 10, 2014 Accepted: October 13, 2014 Online Published: October 15, 2014

doi:10.5539/sar.v4n1p1 URL: http://dx.doi.org/10.5539/sar.v4n1p1

\begin{abstract}
The continuous cultivation of the Rhodes Grass in Batinah costal area and Salalah region of Sultanate of Oman has a negative impact on the overall agriculture system and production. Improvement of the conditions could be achieved by introducing new water policy into farming and using Government supporting tools to motivate farmers and achieve financial sustainability. The new water policy and strategies formed by Government are examined in three cultivated locations in this paper: Salalah location with enough irrigation water, Hanfeet location with low irrigation water and Dawkah location with very low irrigation water. Economic efficiency of the location is evaluated through the Net Present Value and IRR calculation. Within the assumption of the objective evaluation of input parameters, we can expect an acceptable economic efficiency of the investment only in Salalah location. The simplified deterministic evaluation of economic efficiency is formed to identify the relevant risk factors, followed by its quantification by the simulation processes. Taking the risk into account leads to a significant decrease of the economic attractiveness of stakeholders and more Government support is needed to achieve water policy and project sustainability at new location at Hanfeet and Dawkah location.
\end{abstract}

Keywords: Rhodes Grass, water policy, investment project, economic efficiency, simulation model, risk

\section{Introduction}

Over $70 \%$ of fresh water around the world is used for irrigation and water demand for irrigation already exceeds the current supply (IFPRI, 2004). There is a considerable need to increase irrigation efficiency globally as losses during field irrigation, transportation in channels and during field application are major sources of water loss in irrigated agriculture. According to FAO (2002), the overall water use efficiency must be increased, i.e. 'more crop per drop', from $38 \%$ to $42 \%$, between 1998 and 2030 in more than 90 developing countries in order to have sufficient water resources to cover irrigation water demand. The impacts of water scarcity are particularly acute in countries where food and fodder production is heavily dependent on irrigated agriculture, such as in Oman.

In rain-fed agriculture rain is considered as a main source of water to cover water demand of crops. As a result, availability of rain water is considered as the main uncertainty factor, as it is fully dependent on the natural conditions. The risk caused by unpredictable nature is often considered as production risk, which is induced by factors not related to human activities.

Water requirements for crops in irrigated agriculture in Oman are fulfilled by rain as well as underground water. In this case, the availability of water depends on natural as well as human factors. Similar to rain-fed agriculture, natural factors (e.g. precipitation, air temperature) might affect the availability of irrigation water in most regions in Oman. More specific to irrigated agriculture is the availability of irrigation water from underground at Al-Batinah and Salalah plain regions influenced by activities of farmers in these regions and farmers involved in the water management; the interdependence creates difficulties to predict expected amount of irrigation water and increases complexity in decision making in crop and water allocation. Moreover, producers must cope with yield uncertainties caused by underground water availability, diseases and pest damages and price uncertainties caused by changes in markets as well. 
Agricultural farmers in the Al-Batinah and Salalah plains exploiting the good ground water resources took to wide scale cultivation of Rhodes Grass which is easy to grow and crop can be taken out at least six times a year. The excessive use of the precious freshwater has led to ingression of salinity in the area. This causes a grave threat to the ecosystem. The Ministry of Agriculture and Fisheries (MAF) was seized of this problem and carried out an exercise to solve the problem, at the same time meeting the fodder requirements of the livestock to match the needs of a growing population. The concerned ministries apprised His Majesty of the situation and His concern for the environment is also reflected in the policy of the Government on fodder cultivation in Oman. It is decided by the Government to gradually stop the cultivation of Rhodes Grass in Al-Batinah and Salalah plains and at the same time develop substitute areas in the Najed to meet the fodder requirement. The government asked privet companies to establish Joint Stock Company for fodder cultivation at Najed in Dhofar Region.

The Ministry of Regional Municipalities, Environment and Water Resources (MRMEWR) announced new water policy and advised the allowed quantities of water to be extracted out in the project area at Najed. The total quantity of water allowed to be extracted should not exceed 112 million cubic.M/year and water extraction per well restricted to $30 \mathrm{Lit} / \mathrm{Sec}$ only. Moreover, the (MRMEWR) determined the distance and spacing between wells at project area should not be less than $1 \mathrm{KM} \mathrm{X} 1 \mathrm{KM}$ so that water flow should not be affected. Along with this new water policy the Government decided to stop cultivation of Rhodes Grass in Al-Batinah and Salalah plains to cope with salinity problem and uncertainty caused by underground irrigation water supply which gained attention as one of the main subjects needing to be addressed following the drought years in Oman. Government also decided to encourage privet investors by giving capital grants to project to achieve financial sustainability.

The application of new water policy will increase capital and operation cost and includes uncertainty factors which will affect economic efficiency of the resources. The risk and uncertainty are best thought of as representing a spectrum of unknown situations with which an analyst may be dealing, ranging from perfect knowledge of the likelihood of all the possible outcomes at one end (risk) to no knowledge of the likelihood of possible outcomes at the other (uncertainty).

It is not the real-world situation itself, which is either risky or uncertain, but merely the information available to analysts, which defines it as such. All actual project outcomes are unknown, because they occur in the future and are subject to influence by a number of variables, each of which may take different values. If we have reliable historical or forecast data such that a probability distribution can be constructed for such variables, the situation can be modeled as risky. If we do not have such data we can only describe the future in terms of uncertainty. The range of crop yield treated as risky and underground water availability treated as uncertainty in our model.

A quantitative risk analysis can be performed a couple of different ways. One way uses single-point estimates, or is deterministic in nature. Using this method, an analyst may assign values for discrete scenarios to see what the outcome might be in each. For example, in a financial model, an analyst commonly examines three different outcomes i.e. the worst case, best case, and most likely case.

However, there are several problems with deterministic approach analysis as it considers only a few discrete outcomes and ignoring hundreds or thousands of others. It also gives equal weight to each outcome and ignores the interdependence between inputs, and impact of different inputs to the outcome.

\section{Materials and Methods}

From the methodological point of view, the dynamic access model based on the Net Present Value (NPV) and the Internal Rate of Return (IRR) were used for the evaluation of economic efficiency of the different Location and water policy in study area.

\subsection{Net Present Value}

The NPV was used as an evaluation criterion. The net cash flow, calculated by subtracting the cost from the revenue, was discounted by the interest rate to obtain the NPV of the project. If NPV is a function of all both deterministic and stochastic variables, the resulting NPV gets a range of values instead of a single value obtained in a conventional deterministic financial evaluation. NPV is obtained from the below formula.

\subsection{Monte Carlo Simulation}

Monte Carlo simulation is a computational algorithm designed to evaluate the variability or stochastic of the input variables of a model. It can be used to model the effects of key variables on the NPV of a given proposal. The process involves, first, the identification and assessment of the key variables. For each key variable, we fit a probability density function that best describes the range of uncertainty around the expected value. 


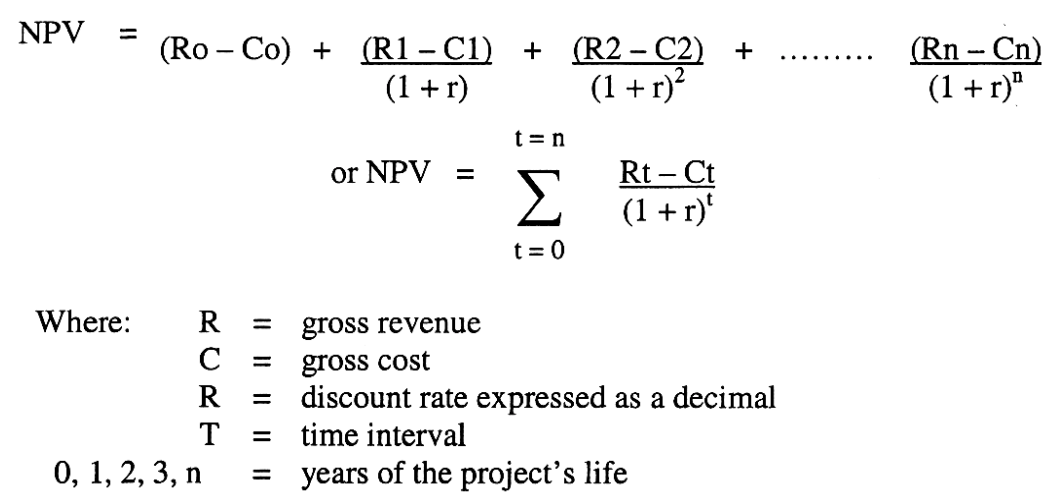

The model including these variables is then calculated using randomly-generated input values taken from the underlying probabilistic distribution function. The computer model combines these inputs to generate an estimated outcome value for (NPV) and (IRR). The process is repeated (ten thousand times).

Monte Carlo simulation model is currently regarded as the most powerful technique for cash-flow analysis. It is useful when there are many variables with significant uncertainties. The more complex the project and the more risks and uncertainty that are associated, the more valuable Monte Carlo simulation analysis will be.

A dynamic, stochastic, mechanistic simulation model of a Rhodes Grass farming was developed in three locations to evaluate the economics of investments in farming and water policy implementation. The model was designed to characterize agriculture parameters and economical complexities of a Rhodes Grass farming within a partial budgeting framework by examining the cost and benefit streams coinciding with investment in desert farming and high risk areas. A secondary aim was to develop the model in a manner conducive to future utility as a flexible, farm-specific decision making tool. The basic deterministic model was constructed in Microsoft Excel 2010 (Microsoft, Seattle, Washington). The @Risk 5.7 (Student Version for Academic Use) from (Palisade Corporation, Ithaca, New York) add-in for Excel was utilized to account for the stochastic nature of key variables in the Monte Carlo simulation model.

\subsection{Model Structure}

The modeling process began by defining a series of inputs to describe the initial status and behavior of the farm system. The underlying behavior of the Rhodes Grass growing system was represented using current knowledge and recorded data from MAF and literature.

The purpose of qualitative risk analysis in this study is to provide a high level of understanding of risks of the project. Such analysis may increase attention of project management and water policy team members to the top risks they need to manage effectively.

Qualitative risk assessment identified risk parameters and estimated the following:

- Risk probability

- Risk impacts on project objectives such as capital cost- operation cost - crop yield and irrigation water policy - project sale volume and revenue. The risk impact built in a probabilistic model during quantitative evaluation

The quantitative risk analysis is performed by selecting the probability of the main key variables and consequence of all individuals risk combined on parameters affecting the project financial performance and cash flows. The result of the analysis includes a probability that a project will meet its quantitative objectives and cash flow projection. All probability distribution of the key parameters are incorporated in to Monte Carlo Simulation Model which allows evaluation and quantified risks as shown in Table 1.

\subsection{Location Models Description and Scenarios}

This section presents the model results in the baseline as well as the results from different scenarios simulations. In addition to the baseline scenarios (Salalah) location, there were two location scenarios were tested. Parameters 
used in the baseline scenario and Najed area scenario reflects an expected water policy and/or crop yield, total sale volume, sale price and per unit cost of production for each farm location.

Table 1. Risk parameters affecting Project DCF in Dynamic Location Models:

\begin{tabular}{lllllll}
\hline Risk & Affects & Distribution & $\begin{array}{l}\text { Absolut/ } \\
\text { percentage }\end{array}$ & $\begin{array}{l}\text { Impacts } \\
\text { Min }\end{array}$ & Most likely & Max \\
\hline $1^{\text {st }}$ year Sale volume & Revenue & Normal & Percentage & 19667 & & 21072 \\
Increase in sales ton & Revenue & Triangular & Percentage & $1 \%$ & $2 \%$ & $5 \%$ \\
Sale Price/ton & Revenue & Triangular & Absolut & 90 & 95 & 100 \\
Unit cost/ton & Cost & Triangular & Absolut & $65 \%$ & $68 \%$ & $70 \%$ \\
Increase in sales price & Revenue & Triangular & Percentage & $1 \%$ & $3 \%$ & $5 \%$ \\
Yield reduction & Revenue & Compound & Percentage & $2 \%$ & $5 \%$ & $7 \%$ \\
Water reduction Probability & Yield & Risksimtable & Absolut & 0.1 & 0.3 & 0.5 \\
Water reduction/year & Yield & Binomial & Absolut & & 0.1 & \\
Water recharge/year & Yield & Binomial & Absolut & & 0.2 & \\
\hline
\end{tabular}

The results of each scenario contribute to the decision making process as they shed light on the potential positive and negative economic and ecological implications of proposed water policy changes. The main parameters changed among the different simulations are presented in Table 2 and a full description of each scenario is presented in the subsequent sections. Each scenario was ultimately designed to understand two primary effects: firstly, changes to project yield and income due to water shortage risk at new developed area and its effect on NPV. Secondly, changes in different levels of underground water availability and its effect on yield and NPV. Three Probabilities of water reduction of (10\%-30\%-50\%) were tested by using Risksimtable Function. The yield reduction of each water level is presented by a Trianguler distribution form ( $8 \%-12 \%-15 \%)$. The water policy use for each location (Coastal Area \& Desert Area) and its implications and effect on yield and NPV were tested for each location. The model simulation produces a range of possible outputs NPV and IRR represented in cumulative probability distributions addressing a level of $90 \%$ confidence for each different outcome.

\section{Results and Discussions}

The analysis in Scenarios 3, 4, 5 and 6 are carried out under the conditions of existing state order and new water policy in place. The situation of increased water scarcity at new farm location at Hanfeet Farm without Government subsidy presented in (Scenario 3) and the introduction of Government subsidy presented in (Scenario 4). These scenarios are all considered under the existing state order and new water policy system.

In model 5 and 6 the proposed scenarios performed under severe water shortage at Dawkah Farm location under the existing state order and new water policy system. Model 5 present the farm without subsidy and model 6 present Government capital subsidies. The results of the model analysis are presented in Tables 5 and 6.

Tables 3 and 4 present the minimum, mean, maximum, CV, and range for NPV in each location. Salalah location has minimum, mean, and maximum NPVs of (17.59) million, 62 181, and 18.04 million, respectively. These NPVs are higher than the minimum, mean, and maximum for the Hanfeet and Dawkah locations. The Hanfeet location returned simulated NPVs of (17.65) million, (4.44) million, and 6.28 million for the minimum, mean, and maximum. The Dawkah location has minimum, mean, and maximum NPVs of (11.75) million, (5.55) million, and 1.49 million. The Dawkah Farm had the lowest range while Salalah Farm had the highest range of all three locations. The simulated relative risk is comparable in Hanfeet and Dawkah locations. The relative risk is higher without Government subsidy in all Farm location because there is greater variability in the capital and operation cost and yield per hectare of Rhodes grass. Expected loss ratio reduced with Government subsidy. 
Table 2. Short description of Location Models and different Scenarios

\begin{tabular}{lll}
\hline Model No. & Scenario name & Scenario description \\
\hline $\begin{array}{l}\text { 1- } \\
\text { Model }\end{array}$ & State order and new water policy not in place (Location without water risk) \\
& $\begin{array}{l}\text { Salalah : } \\
\text { Without subsidy }\end{array}$ & $\begin{array}{l}\text { The baseline examines the expected yield, income, income variance of } \\
\text { crop and water allocation under } \text { usual farming conditions. The base run } \\
\text { reflects the actual situation of Rhodes Grass cultivation at coastal area } \\
\text { without raw material subsidy. Three Probabilities of water reduction } \\
(0.10-0.30-0.50) \text { tested by suing Risksimtable Function. }\end{array}$ \\
\hline $\begin{array}{l}\text { Model } \\
\text { Basic }\end{array}$ & $\begin{array}{l}\text { Salalah : } \\
\text { With subsidy }\end{array}$ & $\begin{array}{l}\text { The baseline examines the expected yield, income, income variance of } \\
\text { crop and water allocation under usual farming conditions. The base run } \\
\text { reflects the actual situation of Rhodes Grass cultivation at costal area with } \\
\text { raw material subsidy. Three Probabilities of water reduction } \\
(0.10-0.30-0.50) \text { tested by suing Risksimtable Function. }\end{array}$ \\
& &
\end{tabular}

State order and new water policy in place (Location with low water risk)

\begin{tabular}{|c|c|c|}
\hline $\begin{array}{lr}3- & \text { Water } \\
\text { scarcity and } \\
\text { new water } \\
\text { policy state } \\
\text { order }\end{array}$ & $\begin{array}{l}\text { Hanfeet : } \\
\text { without subsidy }\end{array}$ & $\begin{array}{l}\text { This scenario is relevant to the case where Rhodes Grass farms moved to } \\
\text { new location at Najed. Project want to secure and gain profit when } \\
\text { insecurity related to water supply is higher and the expected amount of } \\
\text { water in the area is lower than in the baseline scenario. Simulations were } \\
\text { carried under new water policy state order and Government subsidies on } \\
\text { inputs were removed. Three Probabilities of water reduction } \\
(0.10-0.30-0.50) \text { tested by suing Risksimtable Function. }\end{array}$ \\
\hline
\end{tabular}

4- Water Hanfeet :

scarcity and with subsidy

new water

policy state

order
This scenario is relevant to the case where Rhodes Grass farms moved to new location at Najed. The project wants to secure and gain profit when insecurity related to water supply is higher and the expected amount of water in the area is lower than in the baseline scenario. The simulations were carried out under existing state order situation and subsidy. Three Probabilities of water reduction $(0.10-0.30-0.50)$ tested by suing Risksimtable Function.

\begin{tabular}{|c|c|c|}
\hline \multicolumn{3}{|c|}{ State order and new water policy in place (Location with high water risk) } \\
\hline $\begin{array}{lr}5- & \text { Water } \\
\text { scarcity and } \\
\text { new water } \\
\text { policy state } \\
\text { order }\end{array}$ & $\begin{array}{l}\text { Dawkah : } \\
\text { Without subsidy }\end{array}$ & $\begin{array}{l}\text { This scenario is relevant to the case where Rhodes Grass farms moved to } \\
\text { new location at Najed. Investors want to secure their profit when } \\
\text { insecurity related to water supply is higher and the expected amount of } \\
\text { water in the area is lower than in the baseline scenario and Hanfeet area. } \\
\text { The simulations were carried out under existing state order situation. } \\
\text { However, the other model parameters such as input-output prices are also } \\
\text { adjusted for the situation, where state subsidies on capex were removed. } \\
\text { Three Probabilities of water reduction }(0.10-0.30-0.50) \text { tested by suing } \\
\text { Risksimtable Function. }\end{array}$ \\
\hline $\begin{array}{lr}6- & \text { Water } \\
\text { scarcity } & \text { and } \\
\text { new } & \text { water } \\
\text { policy } & \text { state } \\
\text { order } & \end{array}$ & $\begin{array}{l}\text { Dawkah : } \\
\text { With subsidy }\end{array}$ & $\begin{array}{l}\text { This scenario is relevant to the case where Rhodes Grass farms moved to } \\
\text { new location at Najed. Investors want to secure their profit when } \\
\text { insecurity related to water supply is higher and the expected amount of } \\
\text { water in the area is lower than in the baseline scenario and Hanfeet area. } \\
\text { The simulations were carried out under existing state order situation with } \\
\text { Government subsidy. Three Probabilities of water reduction } \\
(0.10-0.30-0.50) \text { tested by suing Risksimtable Function. }\end{array}$ \\
\hline
\end{tabular}


Table 3. Minimum, Mean, Maximum, CV, and Range Values of NPV for Salalah, Hanfeet, and Dawkah locations, without Government subsidy

\begin{tabular}{llll}
\hline Item & Salalah & Hanfeet & Dawkah \\
\hline Mean NPV & 62181 & $(4441315)$ & $(5554459)$ \\
Minimum NPV & $(17598320)$ & $(17647894)$ & $(11754193)$ \\
Maximum NPV & 18037151 & 6286159 & 1488082 \\
Range NPV & 35635471 & 23934053 & 13242275 \\
CV & $73.22 \%$ & $-0.67 \%$ & $-32 \%$ \\
Expected loss ratio & 0.49 & 0.74 & 0.89 \\
\hline
\end{tabular}

Table 4. Minimum, Mean, Maximum, CV, and Range Values of NPV for Salalah, Hanfeet, and Dawkah locations, with Government subsidy

\begin{tabular}{llll}
\hline Item & Salalah & Hanfeet & Dawkah \\
\hline Mean NPV & 915448 & $(1846437)$ & $(3013694)$ \\
Minimum NPV & $(20210996)$ & $(15903188)$ & $(10219702)$ \\
Maximum NPV & 21888561 & 9520626 & 4483129 \\
Range NPV & 42099557 & 25423814 & 14702831 \\
CV & $5.88 \%$ & $-1.60 \%$ & $-0.58 \%$ \\
Expected loss ratio & 0.48 & 0.63 & 0.69 \\
\hline
\end{tabular}

Tables 5 and 6 show NPV and IRR analysis for three farms locations and indicates statistical measures used to test different risks associated with investing in three locations. Different results of management within Farm locations are seen due to a different level of income, operation cost and cost of project development. The economic development of incomes and costs as well as investment costs is reflected into the gained level of cash-flow. Salalah location model with a probability of $10 \%$ of underground water reduction got a positive NPV of RO 62181 and 13\% IRR without Government subsidy where as other location got a negative NPV and IRR. 
Table 5. Statistics of Location Models run results - without Government subsidy

\begin{tabular}{|c|c|c|c|c|c|c|}
\hline Models & Model (1) & Model (3) & Model (5) & Model (1) & Model (3) & Model (5) \\
\hline Location & Salalah & Hanfeet & Dawkah & Salalah & Hanfeet & Dawkah \\
\hline \multicolumn{7}{|c|}{ RiskSimtable Function Models test probability of 0.10 Water reduction } \\
\hline Item & NPV & NPV & NPV & IRR & IRR & IRR \\
\hline Mean & 62181 & $(4441315)$ & $(5554459)$ & $13 \%$ & $-4 \%$ & $-11 \%$ \\
\hline Mode & 219762 & $(3604714)$ & $\left(\begin{array}{ll}6 & 093 \\
243\end{array}\right)$ & $11 \%$ & $1 \%$ & $-11 \%$ \\
\hline SD & 4553273 & 2971229 & 1765989 & $16 \%$ & $11 \%$ & $9 \%$ \\
\hline Variance & 2.073 & 8.828 & 3.115 & 0.0267 & 0.0122 & 0.0085 \\
\hline $\mathrm{CV}$ & $73.22 \%$ & $-0.67 \%$ & $-32 \%$ & $1.23 \%$ & $-2.72 \%$ & $-0.82 \%$ \\
\hline Skewness & 0.0222 & 0.0539 & 0.10046 & -0.2989 & -0.4624 & -0.4613 \\
\hline Kurtosis & 3.0568 & 3.0840 & 3.1518 & 2.9637 & 2.9907 & 2.9372 \\
\hline Min & 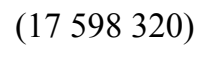 & (17 647894$)$ & (11 754 193) & $-38 \%$ & $-39.0 \%$ & $-39.0 \%$ \\
\hline Max & 18037151 & 6286159 & 1488082 & $67 \%$ & $25.0 \%$ & $14.0 \%$ \\
\hline Range & 35635471 & 23934053 & 13242275 & 105 & 64 & 53 \\
\hline \multicolumn{7}{|c|}{ RiskSimtable Function Models test probability of 0.30 Water reduction } \\
\hline Item & NPV & NPV & NPV & IRR & IRR & IRR \\
\hline Mean & $(15290)$ & (4 491916$)$ & $(5602738)$ & $12 \%$ & $-5 \%$ & $-12 \%$ \\
\hline Mode & $(432601)$ & (3 895384$)$ & $(5277770)$ & $19 \%$ & $0 \%$ & $-11 \%$ \\
\hline SD & 4481585 & 2876585 & 1720489 & $16 \%$ & $11 \%$ & $9 \%$ \\
\hline Variance & 2.008 & 8.275 & 2.960 & 0.0266 & 0.0121 & 0.0085 \\
\hline $\mathrm{CV}$ & $-293.11 \%$ & $-0.64 \%$ & $-0.31 \%$ & $1.33 \%$ & $-2.20 \%$ & $-0.75 \%$ \\
\hline Skewness & 0.0245 & 0.05623 & 0.0998 & -0.2957 & -0.4596 & -0.4558 \\
\hline Kurtosis & 3.0608 & 3.0867 & 3.1558 & 2.961 & 2.9881 & 2.9279 \\
\hline Min & (17 037473$)$ & (17 082 710) & (11 717834$)$ & $-38 \%$ & $-39.0 \%$ & $-39.0 \%$ \\
\hline Max & 17037475 & 5937167 & 1354218 & $66 \%$ & $25.0 \%$ & $14.0 \%$ \\
\hline Range & 34074948 & 23019877 & 13072052 & 104 & 64 & 53 \\
\hline \multicolumn{7}{|c|}{ RiskSimtable Function Models test probability of 0.50 Water reduction } \\
\hline Item & NPV & NPV & NPV & IRR & IRR & IRR \\
\hline Mean & $(93259)$ & $(4542541)$ & 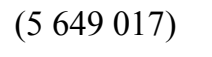 & $12 \%$ & $-5 \%$ & $-12 \%$ \\
\hline Mode & 156536 & (4 395684$)$ & $(5661661)$ & $11 \%$ & $-1 \%$ & $-11 \%$ \\
\hline $\mathrm{SD}$ & 4408356 & 2876585 & 1677563 & $16 \%$ & $11 \%$ & $9 \%$ \\
\hline Variance & 1.943 & 8.828 & 2.8142 & 0.0264 & 0.0120 & 0.0083 \\
\hline $\mathrm{CV}$ & $-47.27 \%$ & $-0.63 \%$ & $-0.30 \%$ & $1.33 \%$ & $-2.20 \%$ & $-0.75 \%$ \\
\hline Skewness & 0.0248 & 0.0562 & 0.1027 & -0.2948 & -0.4602 & -0.4490 \\
\hline Kurtosis & 3.0626 & 3.0868 & 3.1518 & 2.9607 & 2.987 & 2.9172 \\
\hline Min & (17 376 785) & $(17648710)$ & (11 584988$)$ & $-38 \%$ & $-39.0 \%$ & $-39.0 \%$ \\
\hline Max & 16795482 & 5937167 & 1115979 & $65 \%$ & $24.0 \%$ & $13.0 \%$ \\
\hline Range & 34172267 & 23585877 & 12700967 & 103 & 63 & 52 \\
\hline
\end{tabular}


Table 6. Statistics of Location Models run results - with Government subsidy

\begin{tabular}{|c|c|c|c|c|c|c|}
\hline Models & Model (2) & Model (4) & Model (6) & Model (2) & Model (4) & Model (6) \\
\hline Location & Salalah & Hanfeet & Dawkah & Salalah & Hanfeet & Dawkah \\
\hline \multicolumn{7}{|c|}{ RiskSimtable Function Models test probability of 0.10 Water reduction } \\
\hline Item & NPV & NPV & NPV & IRR & IRR & IRR \\
\hline Mean & 915448 & (1 846437$)$ & (3 013694$)$ & $17 \%$ & $3 \%$ & $-6 \%$ \\
\hline Mode & $(978750)$ & (2961 350) & $(3193633)$ & $22 \%$ & $7 \%$ & $-1 \%$ \\
\hline SD & 5381799 & 2962446 & 1755468 & $18 \%$ & $13 \%$ & $11 \%$ \\
\hline Variance & 2.8964 & 8.7761 & 3.0817 & 0.0322 & 0.0172 & 0.0115 \\
\hline $\mathrm{CV}$ & $5.88 \%$ & $-1.60 \%$ & $-0.58 \%$ & $1.06 \%$ & $4.33 \%$ & $-1.83 \%$ \\
\hline Skewness & 0.0531 & 0.0421 & 0.0830 & -0.2074 & -0.4137 & -0.4724 \\
\hline Kurtosis & 3.1052 & 3.1004 & 3.1494 & 2.9531 & 3.0201 & 3.0419 \\
\hline Min & (20 210 996) & (15 903 188) & (10 219 702) & $-39 \%$ & $-38.0 \%$ & $-50 \%$ \\
\hline Max & 21888561 & 9520626 & 4483129 & $78.0 \%$ & $41 \%$ & $26 \%$ \\
\hline Range & 42099557 & 25423814 & 14702831 & 117 & 79 & 76 \\
\hline \multicolumn{7}{|c|}{ RiskSimtable Function Models test probability of 0.30 Water reduction } \\
\hline Item & NPV & NPV & NPV & IRR & IRR & IRR \\
\hline Mean & 823547 & (1 846369 & $\left(\begin{array}{l}3 \\
0\end{array} 061089\right)$ & $16 \%$ & $2 \%$ & $-6 \%$ \\
\hline Mode & 1258069 & (1 592900$)$ & $\left(\begin{array}{l}3 \\
0\end{array} 032016\right)$ & $21 \%$ & $6 \%$ & $-1 \%$ \\
\hline SD & 5295892 & 2916386 & 1711808 & $18 \%$ & $13 \%$ & $11 \%$ \\
\hline Variance & 2.8964 & 8.5053 & 2.9303 & 0.03201 & 0.0172 & 0.0115 \\
\hline $\mathrm{CV}$ & $6.43 \%$ & $-1.58 \%$ & $-0.56 \%$ & $1.13 \%$ & $6.5 \%$ & $-1.83 \%$ \\
\hline Skewness & 0.0550 & 0.04387 & 0.0840 & -0.2040 & -0.4126 & -0.4621 \\
\hline Kurtosis & 3.1080 & 3.0994 & 3.1538 & 2.948 & 3.0189 & 3.0112 \\
\hline Min & (20 011929$)$ & (15 718503$)$ & (10 219702$)$ & $-38 \%$ & $-39.0 \%$ & $-39 \%$ \\
\hline Max & 21286238 & 9220672 & 4132694 & $77.0 \%$ & $41 \%$ & $25 \%$ \\
\hline Range & 41298167 & 24939175 & 14352396 & 115 & 80 & 64 \\
\hline \multicolumn{7}{|c|}{ RiskSimtable Function Models test probability of 0.50 Water reduction } \\
\hline Item & NPV & NPV & NPV & IRR & IRR & IRR \\
\hline Mean & 731184 & (1 946346$)$ & $(3108686)$ & $16 \%$ & $2 \%$ & $-6 \%$ \\
\hline Mode & $\left(\begin{array}{llll}1 & 103 & 699\end{array}\right)$ & (1 579694$)$ & $(3238805)$ & $21 \%$ & $6 \%$ & $-6 \%$ \\
\hline SD & 5209000 & 2869409 & 1667992 & $18 \%$ & $13 \%$ & $11 \%$ \\
\hline Variance & 2.714 & 8.23351 & 2.7822 & 0.0318 & 0.01698 & 0.0112 \\
\hline $\mathrm{CV}$ & $7.12 \%$ & $-1.47 \%$ & $-0.54 \%$ & $1.13 \%$ & $6.50 \%$ & $-1.83 \%$ \\
\hline Skewness & 0.0547 & 0.04614 & 0.0850 & -0.2023 & -0.4117 & -0.4548 \\
\hline Kurtosis & 3.1097 & 3.0981 & 3.1563 & 2.9506 & 3.0165 & 2.9956 \\
\hline Min & (19 786 265) & 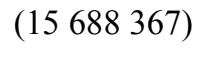 & (9957 601) & $-39 \%$ & $-39.0 \%$ & $-39 \%$ \\
\hline Max & 21250039 & 9107868 & 3951119 & $77.0 \%$ & $41 \%$ & $25 \%$ \\
\hline Range & 41036304 & 24796235 & 10352720 & 116 & 80 & 64 \\
\hline
\end{tabular}


The government subsidy and support increased NPV and IRR of Salalah location to RO 915448 and 17\% respectively. However, the existing Government subsidy could not made farming at Hanfeet and Dawkah location attractive due to low yield and higher investment and operation cost compared to Salalah location.

The statistical analyses measures of central tendency such as mean and mode, measure of variability such as SD and variance of the models and also measure of Skewness and Kurtosis for each model were performed and presented in Table 5 and Table 6. Table 5 shows model results for each farm location outputs (NPV and IRR) without Government investment subsidy. Salalah location got the highest NPV and IRR while Dawkah location got the lowest NPV and IRR. the Government subsidy increase project viability for all loactions.

The required level of confidence for each model is the acceptable level of risk that the investor would take in each project location. The probability of Salalah Farm model to be profitable (NPV >0) was $40 \%$ without subsidy and increased to $60 \%$ with Government capital subsidy at a confidence level of $90 \%$. The spread among minimum and maximum NPV for Salalah farm is higher than other farm locations and also higher with government subsidies in all location. However, this indicates that under government subsidy more farmers are making profit. With government subsidy model distribution skewed to the right and more chance of getting NPV below the mean NPV than expected in a normal distribution and NPV near minimum being observed more than NPV near maximum. It is also means the deviations from the mean are going to be positive. Kurtosis is a measure of the (peakedness) of the probability distribution. As shown in Tables 5 and 6 , the current capital investment subsidies can imply a markedly higher probability of the NPV values near the mean. Thus the current subsidies make Rhode grass crop growing at Najed are less risky.

The models also tested 3 probabilities of water reductions of $10 \%, 30 \%$ and $50 \%$ and its effect to NPV. The NPV decreased with the increase of the probability of water reduction in each model. The Coefficient of Variation or risk degree was calculated to compare NPVs of different location models. The Coefficient of Variation is used to represent the degree of risk for each model. The larger the CV is the greater the risk is. The CVs of NPVs for Salalah Farm Model increased with the increased of probability of water reduction without Government Capital subsidy. Table 6 shows CV increased with water reduction probability increase in Government subsidy scenarios. The Government Capital subsidies reduce degree of risk as presented in Figure 1. Figure 1 shows CV for NPV which represent investor perceptions of risk. It could be stated that all locations are less risky after Government subsidy. However, the variance, SD and CV analysis shows the limitation of using one of these analyses alone as a measure for risk evaluation. Consider two normal distributions of outcomes i.e. NPV and IRR with identical CV and variances but different means. Everyone will prefer the one with the positive and higher mean such as Salalah Farm Location which reflects the actual situation of Rhodes Grass cultivation without new water policy implementation.

The analysis also shows that government subsidy should continue to encourage farmers to cultivate fodder and Rhodes grass crop to feed livestock at the Dhofar region which comprise $58 \%$ of the total population of cattle and $60 \%$ of the total camel population in Oman. Government should also examine and incorporate other subsidies program to make Rhodes grass cultivation at new developed desert area more attractive.

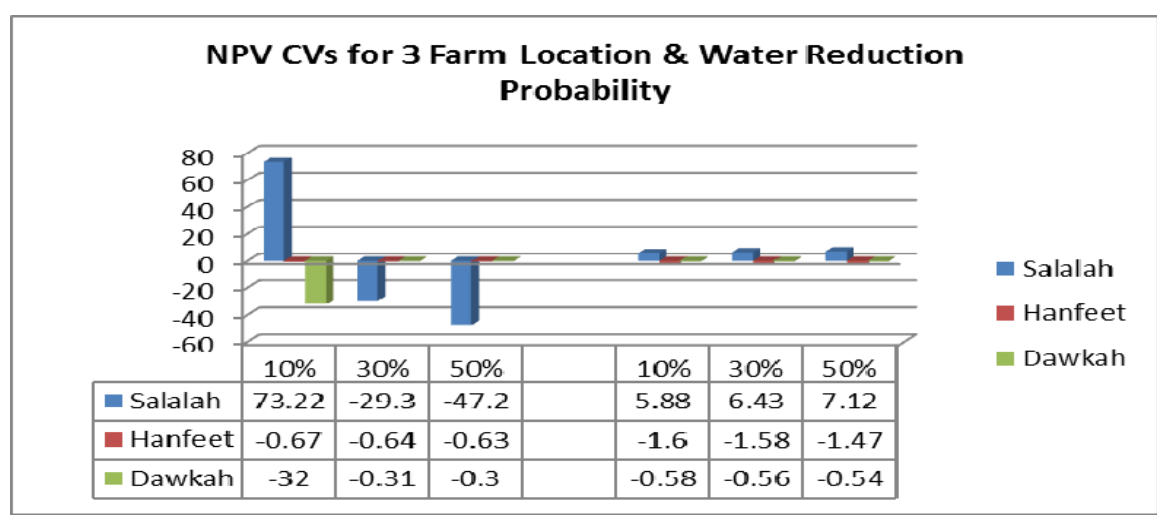

Figure 1. NPV CVs for three Farm location and three water reduction probabilities with \& without Gov. subsidy

Although the NPV analysis for three farm locations with and without Government subsidy indicates that the NPV of each Farm location improved with Government subsidy. But the analysis also shows that the new 
locations recommended by Government Authorities at Najed Area such as Hanfeet and Dawkah are still getting a negative NPV and Government subsidy could not recover losses. However, this shows additional support should be given to farms at new location at Najed.

Figure 2 presents IRR analysis for three farm locations with and without Government subsidy. Farm location and underground water shortage parameters are tested at Hanfeet and Dawkah location. The cumulative distribution of IRR for Hanfeet farm indicates that probability of getting IRR $\leq 0$ is $60 \%$ without subsidy and $40 \%$ with subsidy. Dawkah farm model shows IRR $\geq 0$ with a confidence of $40 \%$. The models analysis shows that IRR are affected with yield reduction and insufficient irrigation water at Hanfeet and Dawkah farms.

The study reveals that the best method for economic feasibility analysis of growing Rhodes Grass at Najed area is Monte Carlo simulation and dynamic model because it gives the probability of success, probability of positive returns, and ending cash reserves. These three variables help stakeholders and policy makers to make a decision based on probabilities instead of worst, best, and average estimated outcomes.

The study also reveals that project location greatly affect the economic success of agribusiness. Location and regional differences in the cost of capital, input costs, availability of water inputs, and transportation costs, all add risk when evaluating alternative locations. The objective of this study is to compare three alternative locations in Najed area for a Rhodes grass production facility under a probabilistic framework and water level reduction. The study confirmed that the method used in this study for water policy decision-making analysis under risk environment is useful as it estimated the distribution for each alternative location's NPV using simulation. The study finally ranked each Farm location based on the characteristics of the simulated NPV distribution and probability of getting positive NPV as showing in Figure 2.

\section{Salalah Location}

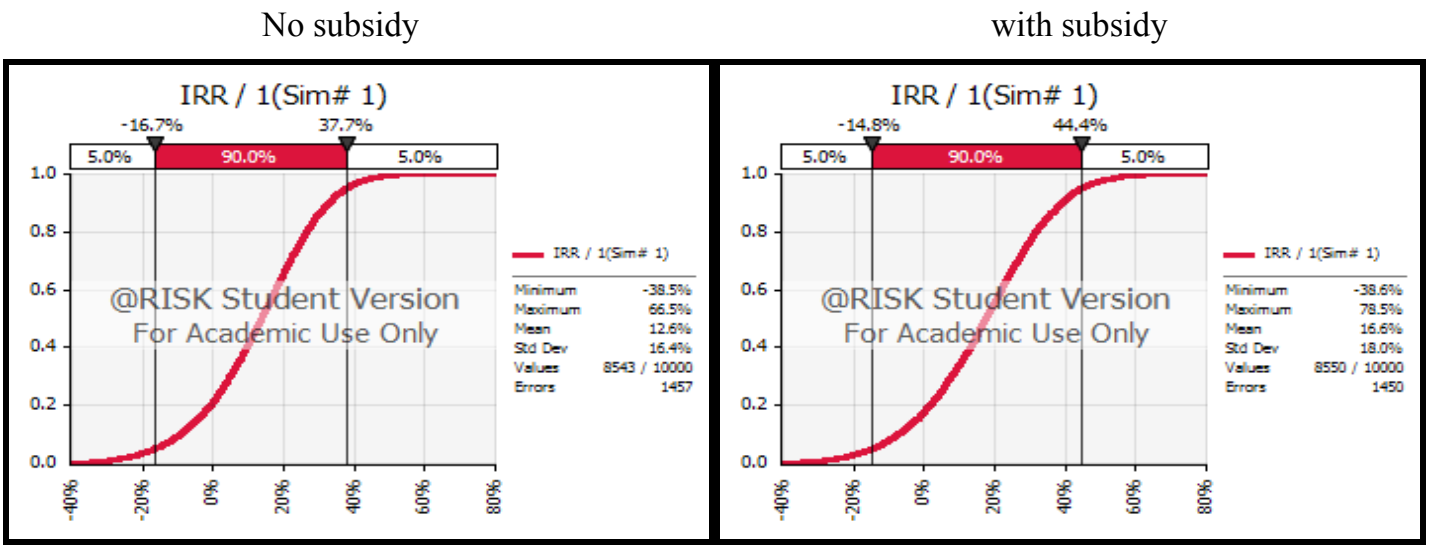

\section{Hanfeet Location}

No subsidy

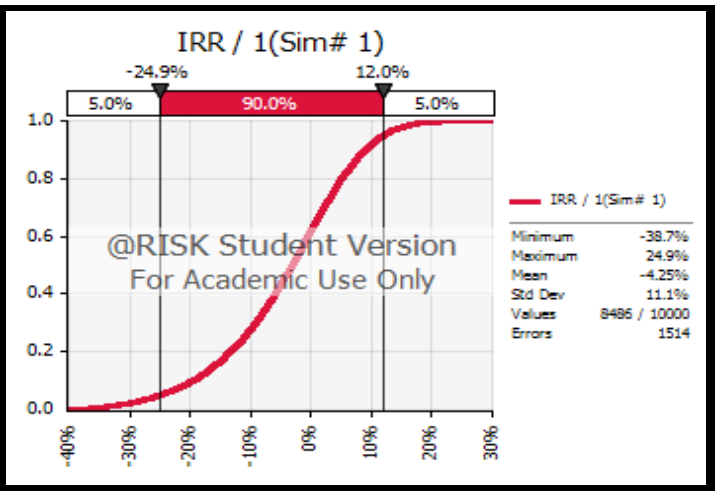

with subsidy

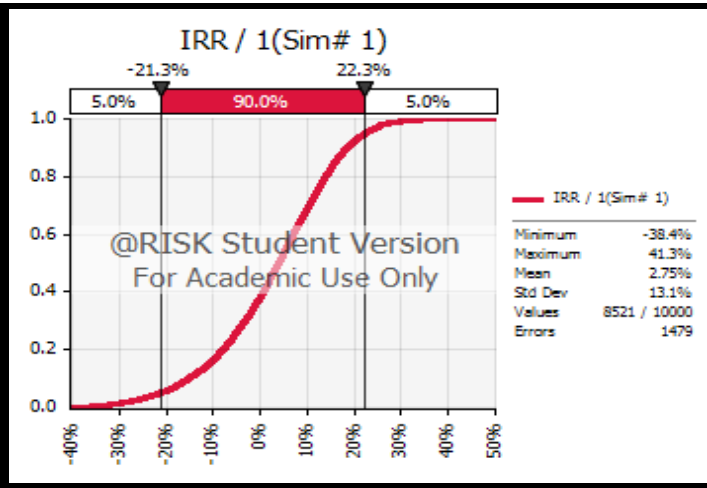




\section{Dawkah location}

No subsidy

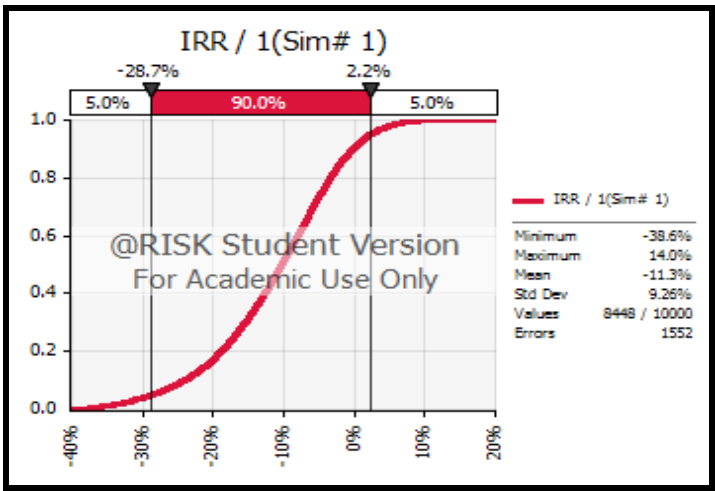

with subsidy

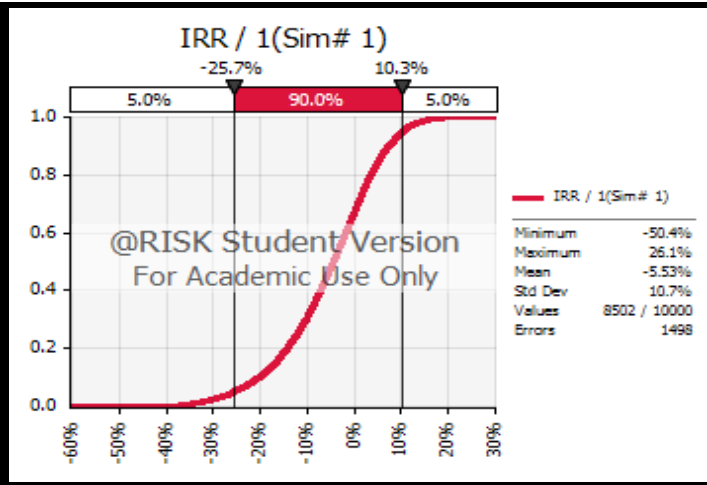

Figure 2. Cumulative Probability Distribution of project returns IRR for 3 Farm Location with and without Government subsidy

\section{Conclusion}

New water policy implemented at new developed Najed area to sustain underground water increase capital and operation cost of the project and reduced project viability. Monte Carlo Simulation model used to incorporate water shortage and new water policy impact in the project appraisal and enhance decision making.

The dynamic MCS model used in this study highlights project areas that need further investigation. It aids the reformulation of projects and water policy to suit the attitudes and requirements of the investor. A project may be redesigned to take account for the particular risk predispositions of the investor and risk could be allocated to parties who are best able to manage and mitigate the risk.

The Government capital cost subsidy given to Najed Project of R.O. 11.26 Million reduced project loss for Hanfeet and Dawkah location, but could not make project attractive to investors and desert farming.

The risk analysis shows that NPV distribution is right skewed and most of the NPV below the mean. Although the Government subsidy makes NPV distribution more symmetric for all level of water reduction, but government should introduce more subsidy programs to make desert farming more attractive investment.

\section{References}

Asian Development Bank. (2002), Handbook for integrated risk analysis in the economic analysis of projects. Manila, Philippines.

David, T. H. (2004). Using quantitative risk analysis to support strategic decisions neighbourhood of Z."1 Published in Consult GEE Executive Briefings in Business Risk Management, Thomson GEE, London UK.

FAO. (2002). Crop and Drop Making the best use of water for agriculture. Food and Agriculture Organization of the United Nations, Viale delle Terme di Caracalla, 00100 Rome, Italy.

Gill, R. C. (2002). A stochastic feasibility study of Texas ethanol production: Analysis of Texas State Legislature ethanol subsidy. Unpublished M.S. thesis, Department of Agricultural Economics, Texas A\&M University, College Station, Texas.

IFPRI. (2004). Assuring Food and Nutrition Security in Africa by 2020 Prioritizing Actions, Strengthening Actors and Facilitating Partnerships. Retrieved from http://www.ifpri.org/pubbs/books/vi24.pdf

James, W. R., Brian, K. H., Joe, L. O., \& R. Chope Gill II (2007). Including Risk in Economic Feasibility Analyses: The Case of Ethanol Production in Texas. Journal of Agribusiness, 25(2), $115 \mathrm{~S} 132$.

Massimo, F. (2008). Guide to Cost-Benefit Analysis of Investment Projects. EU Commission.

Monacciani, F. (2011). Risk assessment for development projects: An integrated approach. Journal of Applied Sciences, 11(4), 743-747. http://dx.doi.org/10.3923/jas.2011.743.747 
Omer, E. (2008). Uncertainty assessment for the evaluation of net present value of a mineral deposit. Master of Science Thesis submitted to The Graduate School of Applied and Natural Sciences of Middle East Technical University, Ankara, Turkey.

Qiu, L. G. (2001). Development of risk analysis models for decision-making in project management. PhD Thesis submitted to School of the Built Environment, Napier University, Edinburgh, UK.

Quiroga, S., Fernandez-Haddad, Z., \& Iglesias, A. (2010). Risk of water scarcity and water policy implications for crop production in the Ebro Basin in Spain. Hydrology and Earth System Sciences Discussions Journal, 7, 5895-5927.

Richardson, J. W., \& Mapp, Jr. H. P. (1976). Use of Probabilistic Cash Flows in Analyzing Investment Under Conditions of Risk and Uncertainty. Journal of Agriculture and Applied Economics, 8, 19-24.

Richardson, J. W., Klose, S. L., \& Gray, A. W. (2000). An Applied Procedure for Estimating and Simulating Multivariate Empirical (MVE) Probability Distributions in Farm Level Risk Assessment and Policy Analysis. Journal of Agriculture and Applied Economics, 32(2), 299-315.

Richardson, J. W., Schumann, K., \& Feldman, P. (2004). Simulation for Applied Risk Management. Department of Agriculture Economics, Texas A\&M University.

Savvakis, C. S. (1994). Risk analysis in investment appraisal. Project Appraisal Journal, 9(1), 3-18. http://dx.doi.org/10.1080/02688867.1994.9726923

Water Science and Technology Association, and Omani Government-Ministry of Regional Municipalities and Water Resources. (2010). Water sustainability in GCC countries - The Need for a Socio-Economic and Environmental Definition. WSTA 9th Gulf Water Conference, Muscat, Sultanate of Oman.

\section{Copyrights}

Copyright for this article is retained by the author(s), with first publication rights granted to the journal.

This is an open-access article distributed under the terms and conditions of the Creative Commons Attribution license (http://creativecommons.org/licenses/by/3.0/). 